\title{
FACTORS INFLUENCING STRATEGIC USE OF WEB- BASED PLATFORM AND ITS IMPACT ON EDUCATION AT UNIVERSITY
}

\author{
Tatjana Vasiljeva
}

Riga International School of Economics and Business Administration, RISEBA (LATVIA)

\begin{abstract}
Introducing web-based platforms in education process opens new era of technology for learning including huge challenges in education. Web-based learning could be considered as essential component fostering online learning and teaching. Various factors influencing the teachers while applying study materials in e-learning platform are investigated in the given research study. The author offers an indicative pattern of a standard content of eteaching materials, and investigates to what extent teaching materials available in MOODLE correspond to this standard pattern for ensuring comprehensive web-based e-learning and supporting effective collaboration system for the students and educator. For assessment the completeness level of e-materials available the composite coefficient is recommended as useful tool for educators who are interested in developing e-learning and e-teaching.
\end{abstract}

Keywords: Web-based platform, course management system MOODLE, empirical study, study course e-materials, composite coefficient, completeness level.

\section{Introduction}

With the advent of new technological era in Information and Communication technology (ICT) web-based e-learning platforms allow educators to construct effective online learning study courses uploading various study materials like syllabus, content, learning instructions, assignments, etc. E-learning platform allows usage of a wide range online learning tools as forums, discussions, e-mail messaging combining face-to-face and online approaches for better delivering of study materials and effective learning. Many researchers (Salmon, 2004; Kibble, Kingsbury, Ramirez, Schlegel, \& Sokolove, 2007; Taradi, Taradi, Radic, \& Pokrajac, 2005; Cole, \& Foster, 2007) consider electronic course management systemas effective tool for improving students' skills. This and similar webbased platform could be used for implementing study courses evaluation, facilitate collaborative learning and enhance students' learning (Taradi et al, 2005). RISEBA University has introduces e-learning platform Moodle for all Study Programmesfollowing the experience of other Universities worldwide and recommendations and suggestions announced by many educators stating that blending e-learning together with habitual face-to-face learning could foster an active and deep approach for learning that enhance the intended learning outcomes (Dantas, \& Kemm, 2008; Davis, Wythe, Rozum, \& Gore, 1997).

Other researchers express the strong necessity for a flexible teaching and learning approach and possibility for offering the students a variety of different study materials in modern formats in order to meet their requirements across the university and campuses including the possibility learn from home (Ynoue, 
2010) with a particular focus on collaborative learning processes and feedback (Alexander, 2006; Herrington, Oliver, \& Reeves, 2006; Masari, 2013). "Elearning platforms made their place in business rather quickly because they allow more efficient-use of material and human resources" (Stoica, \& Valceanu, 2013). The author of given research agreed with the approach for collaborative web-based learning that provides the definition of E-tivities as "framework for enhancing active and participative online learning by individuals or groups, that is low-cost, reusable, customised and scalable". At the same time it should be mention that "only few academics or teachers have all the necessary skills or either time or the desire to acquire them for comprehensive using of web-based tools" (Salmon, 2002).

The research objective: to analyse data about web-based e-learning platform Moodle usage at a University, identify the influential factors and propose the approach for the assessment of existing online materials completeness.

The first research question was to investigate what factors and managerial activities could foster educators for wide usage of e-learning platform.

Taking into account rapid evolution of ICT tools including mobile learning possibilities (Traxler, 2009), widely disseminating massive open online courses (MOOC) (Khan, 2012) considered as the most significant educational innovation in 2012, every University should consider and reflect on about the raising of teaching and learning quality for ensuring sufficient and growing number of the students.

The second research question was to propose the model for assessment the level of completeness of online study materials in e-learning platform.

The author has suggested an approach for apprizing Study courses' online materials and model for assessing to what extent these online materials uploaded in e-learning platform correspond with necessary study materials in paper form.

The research methods: the methods used logical analysis of literature sources, theoretical framework of e-learning teaching, quantitative analysis of the data gathered by investigation the factual situation with Moodle at RISEBA University and qualitative analysis of the interviews with several faculty at RISEBA and other higher educational institutions in Latvia.

\section{Theoretical Framework}

For online learning participants need to be supported through a structured process (Salmon, 2002). The author recommends using Salmon's five stage model for designing and running online teaching and learning activities showing how to motivate online participants and to pace e-learners through Study Programmes. 


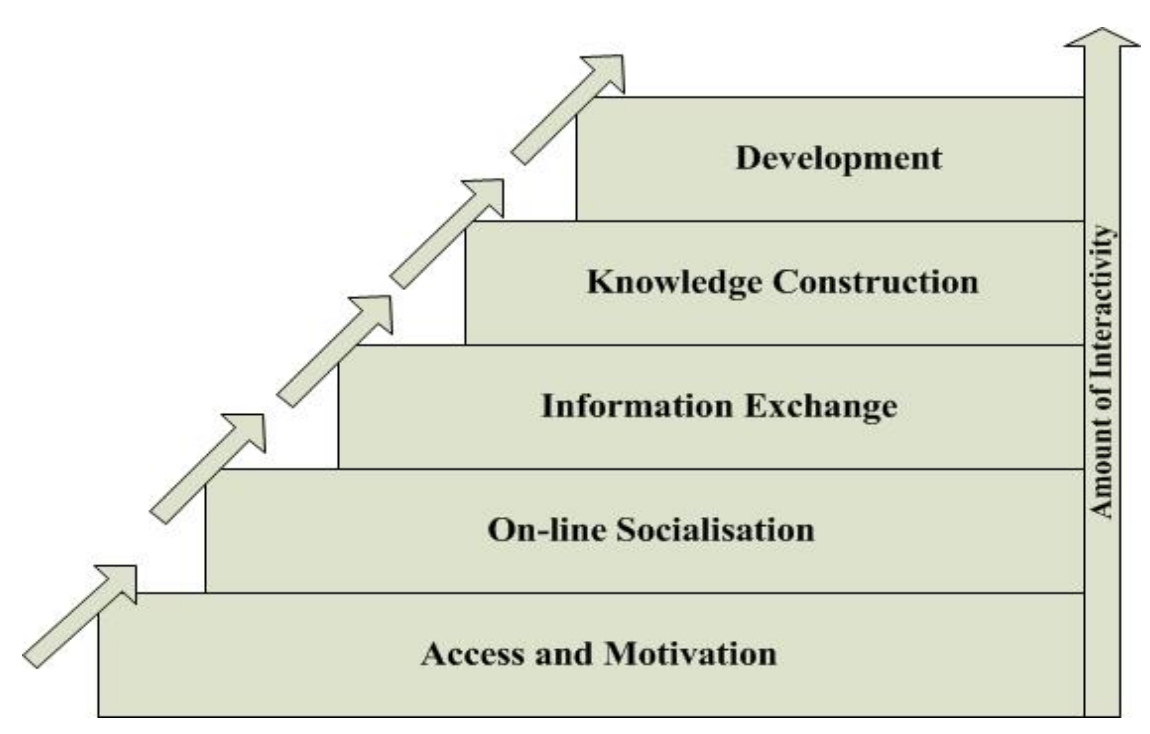

Figure 1 Gilly Salmon's five phase model (Salmon, 2002)

This model comprises five stages (called also as phases) when students should do and complete several tasks and assignments for moving to the next stage by collaborative learning individually, in subgroups and with teacher. Stage 1 ensures bringing students online, Stage 2 facilitates them for working together. At Stage 3 students are confident working in online virtual e-learning platform, while Stage 4 gives the solid basic for students being more collaborative, discussing different points of views, analysing study-cases and negotiating. Stage 5 provides wide room for students independently working in the fields studied including a variety of self-assignments and thesis performing.

But what are we expecting from faculty to be able working in abovementioned framework? The author tries to identify what knowledge, skills and experience do they need for having self-confidence and be fully ready working in webbased learning environment in highly professional way.

In previous research papers (Vasiljeva \& Kremer, 2012) analysing the data about e-learning platform Moodle usage at RISEBA since 2009 the author recognizes the set of factors impacting the successful introduction of virtual learning environment at the University. These factors could be grouped by its' nature in four areas - see the Figure 2.

In the field of socio-psychological aspect we could identify the factors like the shortage of appropriate knowledge and skills causing unsure and insecure faculty' behaviour in online platform supplemented by high level of fear and worry. Even effective tutoring and training process for faculty does not always can ensure obtaining necessary knowledge and skills operate in e-environment taking into account very sensitive nature and sophisticated issues of human being psychology that is very peculiar for academic personnel. 


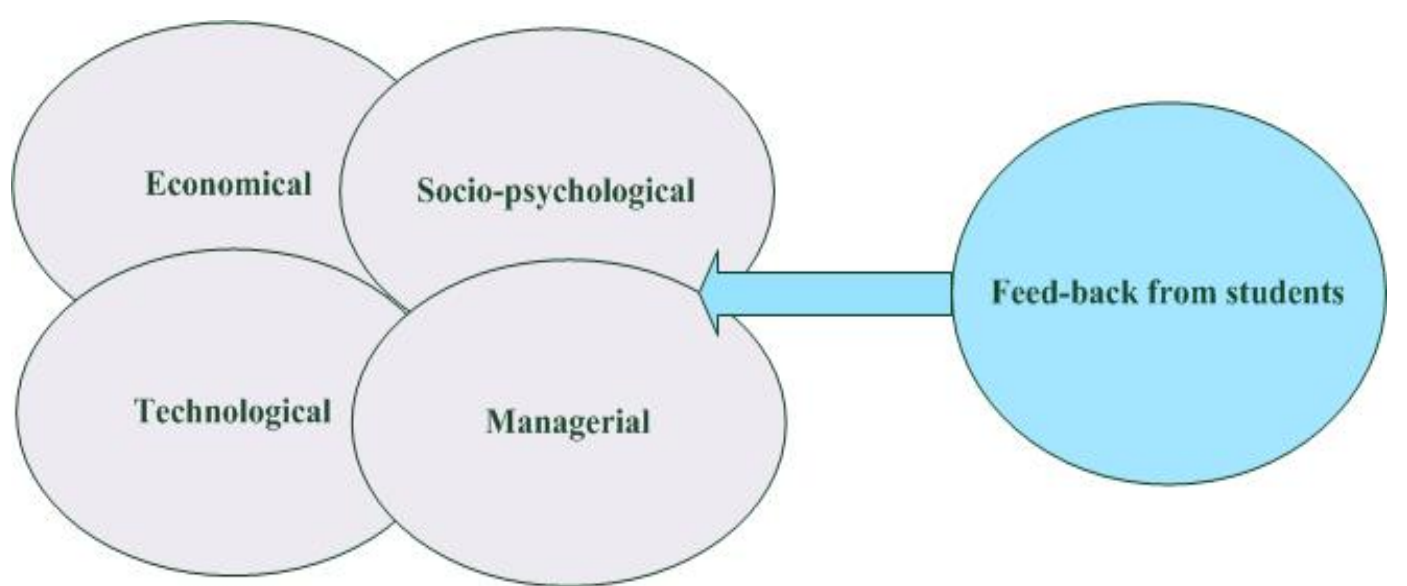

Figure 2 Factors influencing e-learning platform introduction at a University

Economical issue plays great role in persuasion the faculty for active operation in online mode. Proper motivation should be considered as extremely important leverage fostering e-courses preparing and raising faculty interest for creating and maintaining Study courses in Moodle. Either additional salary or another type of bonuses is especially important for following up this process and motivate faculty who do not of contribute. Another possibility for facilitating financial motivation of faculty could be salary compensation model that is based on a estimation of an appropriate criteria like the existence of online study materials and is built-in in salary rate.

The author supposes that technological issue should not be under evaluating being one of the most relevant key factors in online platform introduction. The existence of briefly available training environment for faculty online training sessions, well-developed training instructions as paper-based as online helps, one or several designated tutors who is able to assist faculty in familiarization of e-platform allow achieve more flexibility in faculty training and significantly improved their performance.

Strong top management position and clearly announced decision for introducing e-learning platform as only one exclusive tool for teaching and learning should be considered as vitally important managerial issue that encourage academic personnel for operating in new virtual environment.

The analysis of students' questionnaires and surveys and their feed-back about usage of online platform shows that students highly appreciate the existence of e-courses in Moodle as they are able access every needed teaching component via internet that definitely promotes the learning outcomes.

In the present study the author evaluated the impact of managerial efforts for facilitating Moodle implementation at the RISEBA University trying to develop the pattern for assessing the completeness of online study materials. 


\section{Research methodology for analyse the completeness of e-courses at a University}

The methods for gathering the primary data.For investigating to what extent faculty are ready for e-courses offering the author gathered the data about elearning platform Moodle usage at RISEBA University in years $2011-2013$. Two methods were chosen for gathering the primary data. The first method was an interview for qualitative research approach (Robson, 2011) taking into account such kind of approach could allow focusing on information depth and investigating complex data gained during the discussions with 13 faculty at RISEBA both very active and non-active users of virtual learning environment. These faculty were interviewed for identifying the most important issues impacting usage of online teaching tools.

The second method for collecting primary data was the analysis of software platform Moodle database copies for appropriate years (2011, 2012 and 2013) that contained factual data about online study materials. The exploratory work was conducted analysing the existing online materials of 50 Study courses through these years, the research was done during December 2013 - January 2014, taking into account that in this period all study materials should be prepared for coming semester. The Study courses were chosen using random selection from three particular Study Programmes.

Through the cooperation of various faculties, especially manager of distant learning Centre, an indicative pattern of a content of e-course can be defined as shown on the Figure 3. This pattern consists of three main parts.

The first part further called Part A is mandatory study materials which must be unconditional uploaded in e-learning platform Moodle. The second part can be considered as optional part which includes two types of study materials: part B consisting of additional teaching materials, like test and quizzes with multiple choices, audiovisual resources, useful links, etc. The third part $\mathrm{C}$ consisting of at least some e-resources for students' collaboration, like different forums, students splitting in sub-groups for team working, workshops.

Mandatory Part A. Minimal set of study materials - the components.

Study course information: Syllabus with information about study course structure, contact details of faculty, pre-requirements for course, course schedule, facilities available, and intended learning outcomes.

Study course materials: Study lessons, descriptions, lectures notes, presentations, case study descriptions, book references, any additional useful information.

Control assessments: set of assignments for individual and /or team/group working, self-assignments.

Exam: set of exam questions, assignments consisting of main subjects taught during particular study course. 


\section{Optional Part B. Minimal set of additional study materials - the components.}

Test with multiple choices, true-false test: set of questions in particular field of Study courses with pre-defined answers that are shown on random basic for testing students' understanding about the concepts taught.

Audiovisual resources: additional materials for the students who are able to download it or learn online for demonstrating some study cases, innovative technological approaches, main trends and paradigms.

Internet links: these could be links to relevant Internet sites useful and valuable for strengthening the knowledge and competence.

Optional Part C. Minimal set of e-resources for students' collaboration the components.

The author of given research believes collaboration possibilities through set of well-defined e-resources can bring the students the new level of mutual cooperation. These collaboration resources could be at least Forums, Students sub-groups for team working, Workshops, but not only. Every faculty can develop appropriate e-resources types according to specific teaching and learning targets.

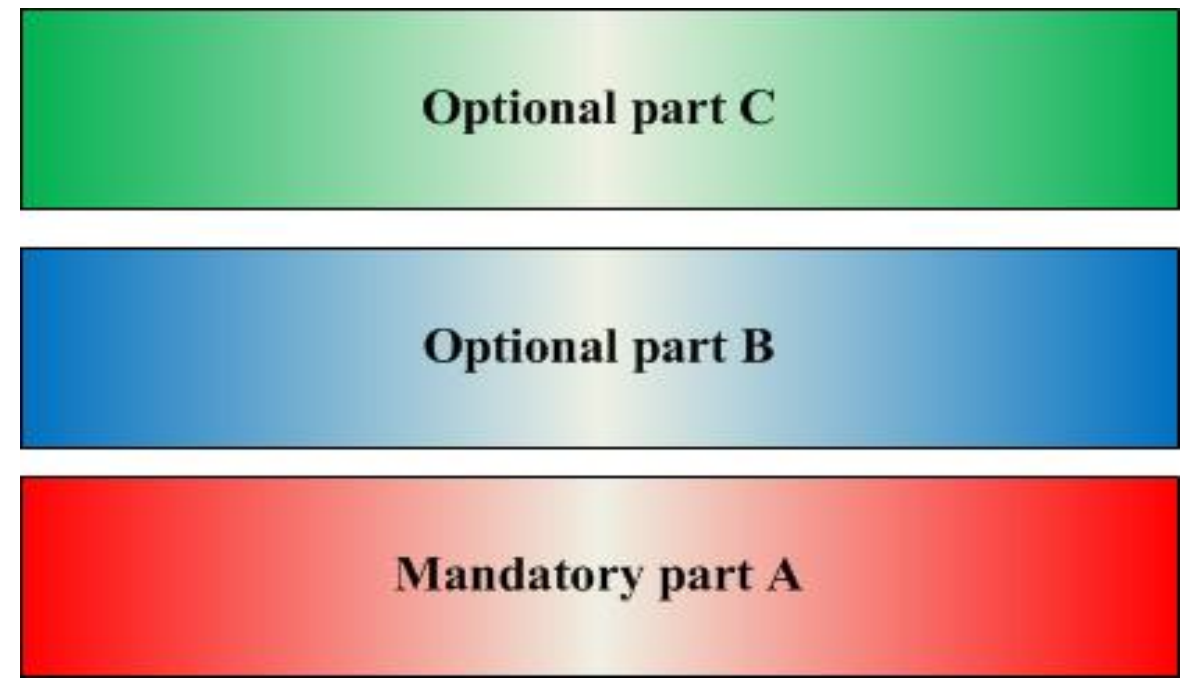

Figure 3 An indicative pattern of a content of e-course

The content of chosen Study courses were analysed according to abovementioned indicative pattern. All the components were assessed according to such algorithm. The number of materials existing in e-platform for every component was enumeratedfor the whole Study Course. The average numbers of corresponding material for each component were calculated depending of the number of Credit Points for each particular Study course.

Each of the above-mentioned components was assigned the particular weight suitable to the importance of every component type. This weight was based on the Conditions and recommendations for RISEBA Distant learning teaching and partly on author assumption about components notability and defined as 


$$
\begin{aligned}
& \sum_{i=1}^{n} \alpha_{i}=1_{\text {where }} \alpha_{i \text { - a weight for each component, } i \text { - a component; }} \\
& \alpha_{i}>0, i=1, \ldots, n \text {. In the given research } i=1, \ldots, 10 .
\end{aligned}
$$

As a result the summary data about e-resource existence for three Study years were obtained for further analysis of the completeness level of study materials in e-learning platform and it' evolution trend. The completeness level was calculated as Composite coefficient according to the formulas below.

Each component influencing the common e-resources level is calculated as

$$
f_{i j}=\frac{F_{i j}-\bar{F}_{j}}{\sigma_{j}}
$$

where $F_{i j}$ - Amount of e-resource available for particular component in particular study course, $i=1, \ldots .10, j=1, \ldots 50$.

$\bar{F}_{j}$ - Average amount of e-resources available for particular component and particular Study course

$\sigma_{j}$ - Standard deviation.

Composite coefficient for assessment the completeness of e-resources for each Study course is calculated as $R_{j}=\sum_{i=1}^{n} \alpha_{i} \cdot f_{i j}$

Restrictions. While analysing the primary data about faculty activity in elearning platform usingsome sensitive aspects were not investigated deliberately taking into account extremely touchy nature of academic environment. Though there is data for recognizing the faculty who was the author of particular study course the author have not investigated whether any correlation between faculty academic degree and Study course e-materials existence in Moodle can be observed. Likewise, the correlation between Study Programme and Study courses belonging to this particular field of education was not investigated in order not to deduce that any study direction is better /worse supported with eresources than other. As Study courses were chosen on random basic, neither faculty gender, age nor the distribution between academic faculty and visiting faculty were analysed. 


\section{The results of the research}

The analysis of primary data about Study courses completeness in e-learning platform Moodle at RISEBA University showed the following results. For better visibility of the graphs the study courses were sorted from smallest to largest according to the amount of e-resources available. Below there are graphs showing the growth of e-resources as relative amount per Study Course recalculated to one credit point in Mandatory Part A, Optional Part B and Part C in Year 2011, 2012, 2013- see Figures 4 - 6.

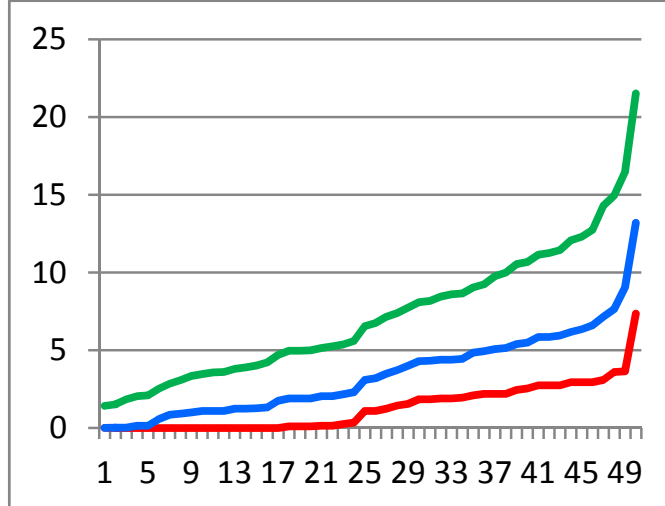

Figure 4 Components in Part A

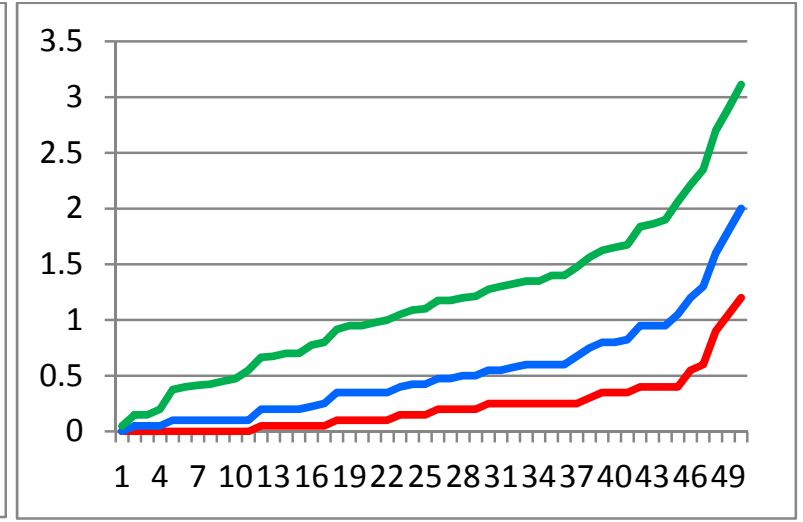

Figure 5 Components in Part B

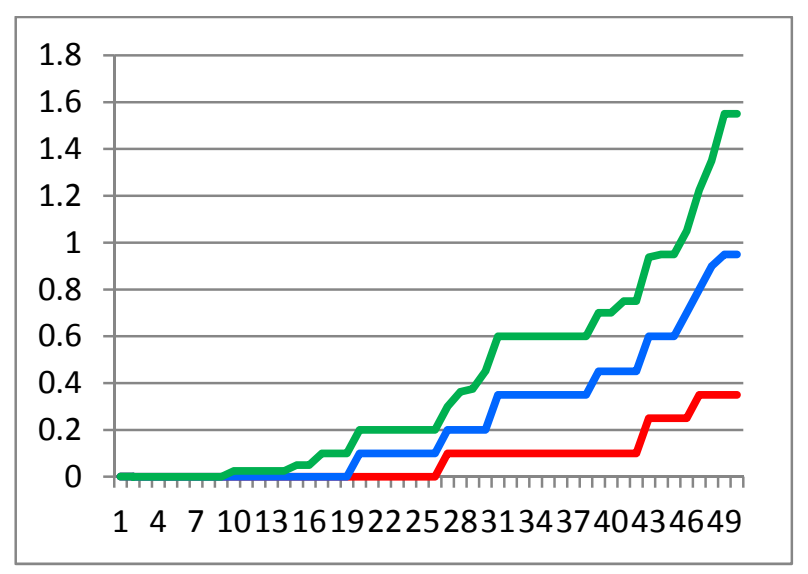

Figure 6 Components in Part C

The author defines the minimal standard e-resource content for 1 credit point Study course as the set of e-resources as stated in Table 1.

Table 1

Standard content of e-resources for 1 credit point Study course

\begin{tabular}{|l|l|c|c|}
\hline & \multicolumn{1}{|c|}{ Component } & $\begin{array}{c}\text { Number of relevant } \\
\text { e-material }\end{array}$ & Weight \\
\hline Part A & 1. Syllabus & 1 & 0,1 \\
\hline & 2. Chapters with Study materials & 4 & 0,30 \\
\hline & 3. Control assessments & 2 & 0,05 \\
\hline & 4. Exam & 1 & 0,1 \\
\hline
\end{tabular}




\begin{tabular}{|l|l|l|c|}
\hline Part B & 5. Test with multiple choices & 1 & 0,05 \\
\hline & 6. Audiovisual materials & 1 & 0,15 \\
\hline & 7. Internet links & 2 & 0,05 \\
\hline Part C & 8. Forum & 1 & 0,05 \\
\hline & 9. Sub-group for team working & 1 & 0,05 \\
\hline & 10. Workshop & 1 & 0,1 \\
\hline
\end{tabular}

The author proposed model for composite coefficient calculation for e-resource completeness level assessment showed the results given in Appendix 1. For standard content of e-resource the completeness level and the appropriate coefficient has the value 1 , what should be considered as the goal for every estudy course.

The composite coefficient $R$ in years $2011-2013$.

\begin{tabular}{|c|c|c|c|}
\hline Study Course & R 2011 & R 2012 & R 2013 \\
\hline 1 & 0 & 0,46875 & 0,84375 \\
\hline 2 & 0,0125 & 0,2375 & 0,7875 \\
\hline 3 & 0,325 & 0,346875 & 0,5234375 \\
\hline 4 & 0,04375 & 0,071875 & 0,471875 \\
\hline 5 & 0,01875 & 0,46875 & 0,603125 \\
\hline 6 & 0,13125 & 0,24375 & 0,428125 \\
\hline 7 & 0,05 & 0,05 & 0,3125 \\
\hline 8 & 0,1375 & 0,053125 & 0,439375 \\
\hline 9 & 0,075 & 0,159375 & 0,359375 \\
\hline 10 & 0,03125 & 0,053125 & 0,470625 \\
\hline 11 & 0,25625 & 0,1375 & 0,63125 \\
\hline 12 & 0,0125 & 0,178125 & 0,358125 \\
\hline 13 & 0,44375 & 0,5125 & 0,515625 \\
\hline 14 & 0,03125 & 0,115625 & 0,709375 \\
\hline 15 & 0,575 & 0,76875 & 0,809375 \\
\hline 16 & 0 & 0,234375 & 0,408125 \\
\hline 17 & 0,0125 & 0,4 & 0,4890625 \\
\hline 18 & 0,0375 & 0,55 & 0,659375 \\
\hline 19 & 0,1125 & 0,34375 & 0,36875 \\
\hline 20 & 0,2375 & 0,76875 & 0,8375 \\
\hline 21 & 0,35625 & 0,3125 & 0,30625 \\
\hline 22 & 0,2 & 0,16875 & 0,5 \\
\hline 23 & 0,0375 & 0,375 & 0,58125 \\
\hline 24 & 0,04375 & 0,515625 & 0,8265625 \\
\hline 25 & 0,0625 & 0,4625 & 0,6 \\
\hline 26 & 0,01875 & 0,134375 & 0,715625 \\
\hline 27 & 0,425 & 0,2875 & 0,84375 \\
\hline 28 & 0,03125 & 0,28125 & 0,325 \\
\hline 29 & 0,38125 & 0,28125 & 0,3546875 \\
\hline
\end{tabular}




\begin{tabular}{|c|c|c|c|}
\hline 30 & 0,4125 & 0,46875 & 0,5375 \\
\hline 31 & 0,14375 & 0,44375 & 0,4703125 \\
\hline 32 & 0,03125 & 0,315625 & 0,58125 \\
\hline 33 & 0,03125 & 0,2875 & 0,36875 \\
\hline 34 & 0,3 & 0,378125 & 0,4921875 \\
\hline 35 & 0,01875 & 0,2875 & 0,6171875 \\
\hline 36 & 0,05625 & 0,46875 & 0,615625 \\
\hline 37 & 0,34375 & 0,4625 & 0,465625 \\
\hline 38 & 0,05 & 0,571875 & 0,728125 \\
\hline 39 & 0,08125 & 0,3875 & 0,6421875 \\
\hline 40 & 0,33125 & 0,35 & 0,728125 \\
\hline 41 & 0,14375 & 0,40625 & 0,509375 \\
\hline 42 & 0,18125 & 0,325 & 0,409375 \\
\hline 43 & 0,05625 & 0,275 & 0,5375 \\
\hline 44 & 0,15625 & 0,203125 & 0,815625 \\
\hline 45 & 0,24375 & 0,2625 & 0,78125 \\
\hline 46 & 0,3 & 0,471875 & 0,55625 \\
\hline 47 & 0,05 & 0,1875 & 0,25 \\
\hline 48 & 0,0125 & 0,35625 & 0,484375 \\
\hline 49 & 0,24375 & 0,25625 & 0,35625 \\
\hline 50 & 0,03125 & 0,15 & 0,3171875 \\
\hline
\end{tabular}

\section{Summary and discussion}

The given research gives the basic for generalising some key findings.

1. The main factors influencing e-learning teaching and learning at a University were discovered. Managerial activities at RISEBA done in Y2011 - 2013 in relevant areas have positively impacted the growth of eresources available in Moodle for teaching and learning.

2. The composite coefficient for modelling and assessment the level of completeness of online study materials in e-learning platform is introduced showing the constant growth of e-resources in Moodle during the Y20112013.

3. It should be mentioned, that supplementation of Study courses with welldesigned e-materials could causes negative events like decreased class attendances and similar. However, the author learned from RISEBA experience that students' attendance at lectures with faculty who provided eresources was not noticeably reduced comparing to faculty who did not offer such kind of teaching material. Even more, in the questionnaires and surveys students marked this aspect as extremely valuable scoring associated faculty teaching skills considerably higher. 
Proceeding of the International Scientifical Conference May $23^{\text {th }}-24^{\text {th }}, 2014$ Volume II

\section{References}

1. Alexander, B. (2006). Web2.0A new wave of innovation for teaching and learning. Educause Review, 41(2), 1-7. Retrieved from https://net.educause.edu/ir/library/ pdf/erm0621.pdf

2. Cole, J., Foster, H. (2007). Using Moodle: Teaching With the Popular Open Source Course Management System. Sebastopol, CA: O'Reilly Media.

3. Dantas, A., Kemm, R. (2008). A blended approach to active learning in a physiology laboratory-based subject facilitated by an e-learning component. AdvPhysiolEduc 32, 6575.

4. Davis, M., Wythe, J., Rozum, J., Gore, R. (1997). Use of World Wide Web server and browser software to support a first-year medical physiology course. AdvPhysiolEduc 17, $1-14$.

5. Herrington, J., Oliver, R., Reeves, T. (2006). Authentic tasks online: A synergy among learner, task and technology. Distance Education, 27(2), 233-248.

6. Khan, S. (2012). One World Schoolhouse: Education Reimagined. New York: Twelve Publishing.

7. Kibble, J., Kingsbury, J., Ramirez, B., Schlegel, W., Sokolove, P. (2007). Effective use of course management systems to enhance student learning: Experimental Biology 2007. AdvPhysiolEduc 31, 377-379.

8. Masari, G. (2013). Moodle platform: an e-learning experience to enhance teaching professional competences of future kindergarten and primary school teachers. eLearning \& Software for Education; Issue 1, 167-181.

9. Robson, C. (2011). Real world research: resource for users of social research methods in applied settings. Third edition. Wiley.

10. Salmon, G. (2002). E-tivities.The key to active online learning. Abingdon: RoutledgeFalmer.

11. Salmon, G. (2004). E-moderating.The key to teaching and learning online. ( ${ }^{\text {nd }}$ Ed). Abingdon: RoutledgeFalmer.

12. Stoica, I., Valceanu, G. (2013). The impact of e-learning platforms in higher education: eLearning and Software for Education, Issue 1, p.258-263

13. Taradi, S., Taradi, M., Radic, K., Pokrajac, N. (2005). Blending problem - based learning with Web technology positively impacts student learning outcomes in acid-base physiology. AdvPhysiolEduc 29, 35-39.

14. Traxler, J. (2009). The evolution of mobile learning. In R. Guy (Ed.), The Evolution of Mo bile Teaching and Learning. Santa Rosa, CA: Informing Science Press.. 1-14.

15. Vasiljeva, T., Kremer L. (2012). E-learning system E-RISEBA - key success factors for implementation. EDULEARN12 Proceedings.

16. Vasiljeva, T., Kremer L. (2013). E-learning system MOODLE at Higher school implementation results. The 2nd Electronic International Interdisciplinary Conference EIIC. Retrieved from http://www.eiic.cz/EIIC-2013_Proceedings.zip.

17. Ynoue, Y. (2010). Cases on Online and Blended Learning Technologies in Higher Education-Concepts and Practices. New York: Editorial Information Science Reference.

Dr.oec. Tatjana Vasiljeva

Riga International School of Economics and Business

Administration, RISEBA (LATVIA), Mežastreet 3, Rīga,

Latvia

E-mail: tatjana.vasiljeva@riseba.lv 